\title{
Appropriateness of aspirin prescribing for primary and secondary prevention of cardiovascular disease in type 2 diabetes in different care settings
}

\author{
Shi Ying $\operatorname{Tan}^{1} \cdot$ Heather Cronin ${ }^{2} \cdot$ Stephen Byrne ${ }^{3} \cdot$ Adrian O'Donovan $^{4} \cdot$ Antoinette Tuthill $^{2}$ (I)
}

Received: 14 November 2020 / Accepted: 10 May 2021 / Published online: 22 June 2021

(c) The Author(s) 2021

\begin{abstract}
Background Type 2 diabetes is associated with an increased cardiovascular risk. Use of aspirin has been shown to be of benefit for secondary prevention of cardiovascular disease in patients with type 2 diabetes; benefits in primary prevention have not been clearly proven.

Aims This study aims to (a) determine if aspirin is prescribed appropriately in type 2 diabetes for primary or secondary prevention of cardiovascular disease (CVD) and (b) evaluate whether there are differences in aspirin prescribing according to where people receive their care.

Design Cross-sectional study

Methods The medical records of individuals with type 2 diabetes aged over 18 years and attending Elmwood Primary Care Centre and Cork University Hospital Diabetes outpatient clinics $(n=400)$ between February and August 2017 were reviewed. Results There were 90 individuals exclusively attending primary care and 310 persons attending shared care. Overall, $49.0 \%$ $(n=196)$ of those were prescribed aspirin, of whom $42.3 \%$ were using it for secondary prevention. Aspirin was used significantly more in people attending shared care $(p<0.001)$. About $10.8 \%$ of individuals with diabetes and CVD attending shared care met guidelines for, but were not prescribed aspirin.

Conclusion A significant number of people with type 2 diabetes who should have been prescribed aspirin for secondary prevention were not receiving it at the time of study assessment. In contrast, a substantial proportion who did not meet criteria for aspirin use was prescribed it for primary prevention.
\end{abstract}

Keywords Cardiovascular disease $\cdot$ Diabetes mellitus $\cdot$ Primary prevention

\section{Introduction}

Type 2 diabetes mellitus is a chronic condition associated with multiple complications and comorbidities. If poorly managed, diabetes can lead to functional limitations, disability, reduced quality of life, and life expectancy.

Antoinette Tuthill

Antoinette.tuthill@hse.ie

Shi Ying Tan

115106519@umail.ucc.ie

Heather Cronin

Heathercronin88@hotmail.com

Stephen Byrne

Stephen.byrne@ucc.ie

Adrian O'Donovan

adrianodonovan@yahoo.co.uk
According to the Irish CODEIRE study (2006), approximately $10.0 \%$ of the Ireland's national healthcare budget was spent on diabetes with nearly half that amount due to hospitalizations attributable to the microvascular and macrovascular complications associated with the disease. A large proportion of these admissions could be prevented

1 School of Medicine, University College Cork, College Road, Cork, Ireland

2 Department of Endocrinology and Diabetes, Cork University Hospital, Wilton, Cork, Ireland

3 School of Pharmacy, University College Cork, College Road, Cork, Ireland

4 Elmwood Primary Care Centre, Frankfield, Douglas, Cork, Ireland 
with adequate blood glucose control and mitigating overall vascular risk [1].

In 2012, diabetes alone claimed 1.5 million lives worldwide [2] with the greatest mortality due to cardiovascular disease (CVD) [3]. Persons with type 2 diabetes have a two to fourfold increased risk of developing CVD, [4] mainly due to increased arachidonic acid metabolism and thromboxane $\mathrm{A}_{2}$ synthesis, resulting in augmented platelet aggregation and a pro-inflammatory substrate. Low-dose aspirin inhibits platelet cyclooxygenase 1 , the key enzyme responsible in thromboxane $A_{2}$ synthesis, subsequently preventing thrombus formation [5].

Multiple studies support aspirin prescription for secondary prevention of cardiovascular events as it reduces mortality, and morbidity from non-fatal vascular events (i.e., stroke or myocardial infarction), and total vascular events, respectively $[6,7]$. With regard to primary prevention, historically persons with type 2 diabetes without a prior history of CVD were recommended to commence on aspirin, as diabetes is considered as a CVD risk equivalent [8]. However, the benefits of aspirin are ambiguous and recent studies including the ARRIVE, ASPREE, and in particular ASCEND trials have resulted in changes to guidelines [9-11].

Generally, the guidelines for aspirin use in primary prevention are contradictory. The American Diabetes Association (ADA) has recommended aspirin use as primary and secondary prevention of CVD in diabetes since 1997 [12] and has updated their guidelines several times with minor modifications. In the recent 2020 guidelines, the advice given is that low-dose aspirin ( $75-162 \mathrm{mg}$ /day) should:

1. Be commenced for secondary prevention in persons with previous angina, MI, vascular bypass procedure, stroke or transient ischaemic attack (TIA), claudication, and/ or peripheral vascular disease (PVD);

2. Be recommended for primary prevention in persons who have more than $10 \%$ increased 10 -year cardiovascular risk, including age $\geq 50$ years old who have one or more major risk factors, such as family history of CVD, hypertension, smoking, dyslipidaemia, or albuminuria.

The American Diabetes Association stated that individuals should not be on aspirin therapy if they are younger than 21 years old, or have any specific contraindications, which include aspirin allergy, bleeding tendency, recent gastrointestinal bleeding, and clinically active hepatic disease. Clinical judgment on a case-to-case basis is required for low-risk patients, such as those aged $<50$ years with one or more risk factors, older patients with no risk factors, or those with 5-10\% 10-year cardiovascular risk [13].

As recent evidence demonstrates that there are limited benefits to aspirin use in the primary prevention setting, both the 2016 European Guidelines on Cardiovascular disease prevention in clinical practice and the latest practical guide to integrated type 2 diabetes mellitus by Irish College of General Practitioners (ICGP) in 2016 [14] have altered their guidelines and do not support routine aspirin use in type 2 diabetes without CVD.

This study aims to investigate the appropriateness of aspirin prescribing in type 2 diabetes by (a) comparing aspirin prescribing in a primary and secondary care setting and (b) determining whether aspirin is being used for primary or secondary prevention of CVD.

\section{Methods}

\section{Study design, population, and sample}

This was a cross-sectional study based on medical records of persons monitored on an outpatient basis. All individuals with type 2 diabetes who attended the Elmwood Primary Care Centre and those attending the diabetes outpatient clinics in Cork University Hospital, a large tertiary referral hospital, from February 2017 to August 2017 were eligible for recruitment. Adults aged over 18 years diagnosed with type 2 diabetes before January 2016 and had at least a period of 3-month follow-up were included. Individuals who failed to attend care for more than a year, those diagnosed with pancreatic insufficiency, cystic fibrosis-related diabetes, and those allergic to aspirin were excluded from the study.

A data collection form was used to record individuals' demographic data (date of birth, current and age of diagnosis, gender, ethnicity), anthropometric data (weight and height), smoking status, and care status (care by GP only or shared care). Blood pressure and the most recent laboratory data, such as $\mathrm{HbA}_{1} \mathrm{c}$, total cholesterol, high-density lipoprotein (HDL) cholesterol, low-density lipoprotein (LDL) cholesterol, and urine albumin:creatinine ratio were documented. In addition, diabetes associated comorbidities (e.g., hypertension, hypercholesterolaemia, ischaemic heart disease, MI, cerebrovascular accident, peripheral artery disease, presence of retinopathy or neuropathy, history of peptic ulcer disease and gastritis), medications prescribed, and use of aspirin or other oral anticoagulation drugs were included in the data collection.

The ICGP's guidelines (adapted from both ADA's and NICE's guidelines) were used as the standard. Target levels for $\mathrm{HbAlc}$ were $\leq 53 \mathrm{mmol} / \mathrm{mol}(\leq 7.0 \%)$ for majority of individuals, and $<48 \mathrm{mmol} / \mathrm{mol}(<6.5 \%)$ for those without CVD, and for those on lifestyle modification or metformin use only. Hypertension was defined as either a systolic blood pressure of $>140 \mathrm{mmHg}$ or diastolic pressure of $>80 \mathrm{mmHg}$, or if the patient was taking antihypertensive medications [14]. 
Individuals were recorded as having CVD if they had a history of either ischaemic heart disease, MI, percutaneous coronary intervention, coronary artery bypass grafting, stroke and/or TIA, and PVD. The 10-year cardiovascular risk for persons with type 2 diabetes without CVD was estimated using the UK Prospective Diabetes Study (UKPDS) risk stratification tool [15]. Individuals who were on aspirin for CAD, stroke/TIA, and PVD were classified under secondary prevention. All others were considered as primary prevention.

\section{Statistical analysis}

Statistical analyses were done using IBM SPSS Statistics version 21.0. Descriptive statistics were used to describe the characteristics of aspirin use among individuals with type 2 diabetes in Cork. Independent $t$-test or Mann-Whitney test was used to compare means between individual groups (primary care and shared care, aspirin and non-aspirin users, primary prevention, and secondary prevention). The chisquare test or Fisher's exact test was used to determine the association between characteristics and these groups. In all hypothesis tests, two-sided tests were used and $p<0.050$ was considered statistically significant. Individual patient data was not identifiable from the final analysis. The Clinical Research Ethics Committee (CREC) of the Cork Teaching Hospitals approved this study.

\section{Results}

\section{Characteristics of the study population}

A total of 400 individuals with type 2 diabetes were recruited into the study, with 90 of those exclusively attending primary care and 310 persons under shared care. There was a male predominance in both groups $(61.1 \%$ in primary care and $57.7 \%$ in shared care). Individuals attending shared care had poorer control of their diabetes, more co-morbidities, and complications. Aspirin was used significantly more in those under shared care $(p<0.001)$. Characteristics of both groups are shown in Table 1.

\section{Aspirin use in a primary and secondary setting}

Overall, nearly half (49.0\%) of the participants in this study were prescribed aspirin. Out of the 204 non-aspirin users, 22 $(10.8 \%)$ were previously on aspirin and $47(23.0 \%)$ were on other antiplatelet/anticoagulant agents. Aspirin users were older $(p<0.001)$, had a diagnosis of diabetes for a longer period $(p<0.001)$, higher $\operatorname{HbA}_{1 \mathrm{c}}(p=0.059)$, and higher systolic BP at their last clinic visit $(p=0.018)$. Aspirin users were also more likely to have diagnosed hypertension $(p=0.001)$ and dyslipidaemia $(p<0.001)$.

\section{Appropriate use of aspirin for primary and secondary prevention of CVD}

All CVD patients under GP care were on aspirin or other antiplatelet/anticoagulant, while $10.4 \%$ of participants under shared care had CVD but were not on any antiplatelet or anticoagulant. On the contrary, $15.2 \%$ and $48.1 \%$ of persons under GP care and shared care respectively were on aspirin despite never having a diagnosis of CVD (Fig. 1).

Forty-seven non-aspirin users who were on other antiplatelet agents/anticoagulants were excluded from the analysis for non-aspirin use, as their use would obviate the need for aspirin. The distribution of aspirin use among patients with CVD is shown in Fig. 2. The use of aspirin among PVD patients was significantly higher than any other group, with $91.7 \%$ patients on aspirin.

Of all participants who were prescribed aspirin, 57.7\% were using it for primary prevention, and $42.3 \%$ were on it for secondary prevention. About $91.2 \%$ of participants in primary prevention for CVD category were under shared care. The 10-year cardiovascular risk calculated using the UKPDS risk engine for patients under primary prevention is shown in Fig. 3. In addition, the study demonstrated that participants in the secondary prevention of CVD group were significantly older $(p=0.001)$. There was no significant difference in terms of diabetes control and cardiovascular risk factors between the two prevention groups.

\section{Discussion}

In this study, $49.0 \%$ of the population was prescribed aspirin, among whom $86.2 \%$ were attending shared care. However, despite such a high prevalence of CVD and the international consensus for aspirin use as secondary prevention for CVD, $[13,14,16] 10.8 \%$ of individuals with CVD, who were attending shared care, were not on aspirin or any other antiplatelet/anticoagulant. This may be due to potential contraindications to aspirin use, such as previous gastrointestinal bleeding, history of peptic ulcer disease, or possible medication interactions.

Primary prevention with aspirin has always been controversial. Multiple randomized controlled trials (RCTs) were conducted on aspirin use in primary prevention of CVD over the past 30 years, notably the British Male Doctors Study (1988), [17] Physicians' Health Study (1989), [18] Early Treatment Diabetic Retinopathy Study (1992), [19] Hypertension Optimal Treatment randomised trial (1998), [20] Thrombosis Prevention Trial (1998), [21] Primary 
Table 1 Clinical characteristics of participants recruited from primary and secondary care settings

\begin{tabular}{|c|c|c|c|c|c|}
\hline Variable & $n$ & Total & GP care only $(n=90)$ & Shared care $(n=310)$ & $p$ value \\
\hline Mean age (SD), years & 400 & $64.3(13.21)$ & $62.3(14.62)$ & $64.8(12.74)$ & 0.113 \\
\hline Males, $n(\%)$ & 400 & $234(58.5)$ & $55(61.1)$ & $179(57.7)$ & 0.568 \\
\hline Mean weight (SD), $\mathrm{kg}$ & 394 & $88.86(20.24)$ & $89.19(18.96)$ & $88.78(20.60)$ & 0.868 \\
\hline Mean body mass index (SD), $\mathrm{kg} / \mathrm{m}^{2}$ & 346 & $\begin{array}{l}31.59 \\
(6.60)\end{array}$ & $\begin{array}{l}31.35 \\
(6.09)\end{array}$ & $\begin{array}{l}31.66 \\
(6.76)\end{array}$ & 0.705 \\
\hline Median duration of diabetes (IQR), years & 400 & $9.0(6.0-15.0)^{\dagger}$ & $5.0(4.0-8.0)^{\dagger}$ & $11.0(7.0-17.0)^{\dagger}$ & $<0.001 \neq$ \\
\hline Smoking status, $n(\%)$ & 400 & & & & 0.001 \\
\hline Current & & $51(12.8)$ & $12(13.3)$ & $39(12.6)$ & \\
\hline Never & & $226(56.5)$ & $65(72.2)$ & $161(51.9)$ & \\
\hline Former & & $123(30.8)$ & $13(14.4)$ & $110(35.5)$ & \\
\hline \multicolumn{6}{|l|}{ Mean Clinical laboratory measurements $( \pm S D)$} \\
\hline $\operatorname{HbA1c}(\mathrm{mmol} / \mathrm{mol})$ & 400 & $57.8(16.03)$ & $53.3(16.85)$ & $59.1(15.57)$ & 0.002 \\
\hline Patients without CVD or on diet/metformin use only & 241 & $54.1(15.40)$ & $52.9(17.59)$ & $54.7(15.23)$ & 0.385 \\
\hline Remaining patients & 159 & $63.3(15.44)$ & $55.9(10.23)$ & $53.8(15.654)$ & 0.102 \\
\hline Total cholesterol (mmol/L) & 395 & $4.36(2.00)$ & $4.81(1.30)$ & $4.23(2.15)$ & 0.015 \\
\hline $\begin{array}{l}\text { HDL cholesterol }(\mathrm{mmol} / \mathrm{L}) \\
\text { Male } \\
\text { Female }\end{array}$ & $\begin{array}{l}381 \\
224 \\
158\end{array}$ & $\begin{array}{l}1.18(0.32) \\
1.09(0.28) \\
1.30(0.33)\end{array}$ & $\begin{array}{l}1.21(0.28) \\
1.14(0.24) \\
1.33(0.30)\end{array}$ & $\begin{array}{l}1.17(0.33) \\
1.07(0.29) \\
1.29(0.34)\end{array}$ & $\begin{array}{l}0.238 \\
0.132 \\
0.532\end{array}$ \\
\hline $\begin{array}{l}\text { LDL cholesterol (mmol/L) } \\
\text { In CVD patients } \\
\text { In non-CVD patients }\end{array}$ & $\begin{array}{l}368 \\
109 \\
259\end{array}$ & $\begin{array}{l}2.33(0.88) \\
2.04(0.76) \\
2.45(0.90)\end{array}$ & $\begin{array}{l}2.71(1.02) \\
2.18(0.73) \\
2.90(1.04)\end{array}$ & $\begin{array}{l}2.22(0.80) \\
2.00(0.76) \\
2.31(0.80)\end{array}$ & $\begin{array}{r}<0.001 \\
0.338 \\
<0.001\end{array}$ \\
\hline Systolic blood pressure $(\mathrm{mmHg})$ & 398 & $134.3(15.58)$ & $132.2(11.68)$ & $134.9(16.50)$ & 0.084 \\
\hline Diastolic blood pressure $(\mathrm{mmHg})$ & 398 & $76.85(10.09)$ & $79.3(9.17)$ & $76.2(10.24)$ & 0.010 \\
\hline \multicolumn{6}{|l|}{ Therapeutic targets not achieved, $n(\%)$} \\
\hline Blood pressure & 398 & $168(42.2)$ & $36(40.4)$ & $132(42.7)$ & 0.703 \\
\hline $\begin{array}{l}\mathrm{HbA}_{1 \mathrm{c}} \\
\text { Patients without CVD or on } \\
\text { diet/metformin use only }(\geq 48 \mathrm{mmol} / \mathrm{L} \text { or } \geq 6.5 \%) \\
\text { Remaining patients }(>53 \mathrm{mmol} / \mathrm{L} \text { or }>7.0 \%)\end{array}$ & 400 & $\begin{array}{l}271(67.8) \\
153(56.5) \\
118(43.5)\end{array}$ & $\begin{array}{l}49(54.4) \\
41(95.9) \\
8(16.3)\end{array}$ & $\begin{array}{l}222(71.6) \\
112(50.5) \\
110(49.5)\end{array}$ & $\begin{array}{l}0.002 \\
0.009 \\
1.000 \S\end{array}$ \\
\hline $\begin{array}{l}\mathrm{HDL} \\
\text { Male }(<1.0 \mathrm{mmol} / \mathrm{L}) \\
\text { Female }(<1.3 \mathrm{mmol} / \mathrm{L})\end{array}$ & 382 & $\begin{array}{l}179(46.9) \\
93(52.0) \\
86(48.0)\end{array}$ & $\begin{array}{l}33(37.9) \\
17(51.5) \\
16(48.5)\end{array}$ & $\begin{array}{l}146(49.5) \\
76(52.1) \\
70(47.9)\end{array}$ & $\begin{array}{l}0.058 \\
0.086 \\
0.441\end{array}$ \\
\hline $\begin{array}{l}\text { LDL } \\
\text { In CVD patients }(>1.8 \mathrm{mmol} / \mathrm{L}) \\
\text { In non-CVD patients }(>2.5 \mathrm{mmol} / \mathrm{L})\end{array}$ & 368 & $\begin{array}{l}161(43.8) \\
63(39.1) \\
98(60.9)\end{array}$ & $\begin{array}{l}52(60.5) \\
15(28.8) \\
37(71.2)\end{array}$ & $\begin{array}{l}109(38.7) \\
48(44.0) \\
61(56.0)\end{array}$ & $\begin{array}{r}<0.001 \\
0.270 \\
<0.001\end{array}$ \\
\hline \multicolumn{6}{|l|}{ Past medical history $n(\%)$} \\
\hline Diagnosed hypertension & 400 & $221(55.3)$ & $36(40.0)$ & $185(59.7)$ & 0.001 \\
\hline Dyslipidaemia & 400 & $177(44.3)$ & $27(30.0)$ & $150(48.4)$ & 0.002 \\
\hline Coronary heart disease & 400 & $86(21.5)$ & $20(22.2)$ & $66(21.3)$ & 0.850 \\
\hline Cerebrovascular accident & 400 & $40(10.0)$ & $8(8.9)$ & $32(10.3)$ & 0.690 \\
\hline Peripheral vascular disease & 400 & $16(4.0)$ & $0(0.0)$ & $16(5.2)$ & $0.028^{\S}$ \\
\hline Peptic ulcer disease & 400 & $11(2.8)$ & $3(3.3)$ & $8(2.6)$ & $0.716^{\S}$ \\
\hline Gastritis & 400 & $17(4.3)$ & $7(7.8)$ & $10(3.2)$ & $0.074^{\S}$ \\
\hline \multicolumn{6}{|l|}{ Microvascular complications, $n(\%)$} \\
\hline Diabetic retinopathy & 363 & $82(22.6)$ & $9(10.6)$ & $73(26.3)$ & 0.002 \\
\hline Diabetic neuropathy & 400 & $82(20.5)$ & $10(11.1)$ & $72(23.2)$ & 0.012 \\
\hline Albuminuria & 350 & & & & \\
\hline Microalbuminuria & & 75 (21.4) & $9(15.8)$ & $66(22.5)$ & 0.137 \\
\hline
\end{tabular}

The distribution is skewed to the right

Mann-Whitney test

${ }^{\S}$ Fisher's exact test 


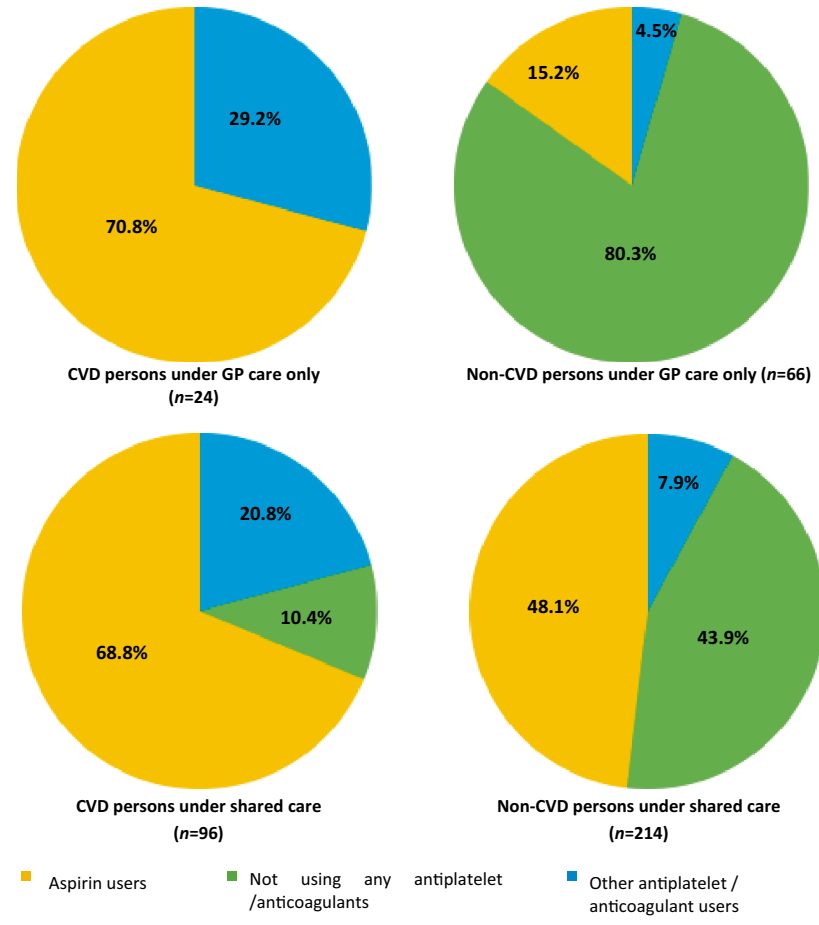

Fig. 1 Appropriateness of use of aspirin in participants with type 2 diabetes attending primary or secondary care

Prevention Project (2001), [22] and Women's Health Study (2005), [23] among others. A meta-analysis of four of the mentioned RCTs reported a significant reduction of all cardiovascular events by $15.0 \%$, and myocardial infarctions by $30.0 \%$. However, this was balanced with an increased risk of bleeding by $69.0 \%$.[24]. Two other meta-analyses done in 2011 reported similar findings - a decrease in total cardiovascular events, and non-fatal MI, but no statistical reduction in stroke, or all-cause mortality [25, 26]. Berger et al. [26]

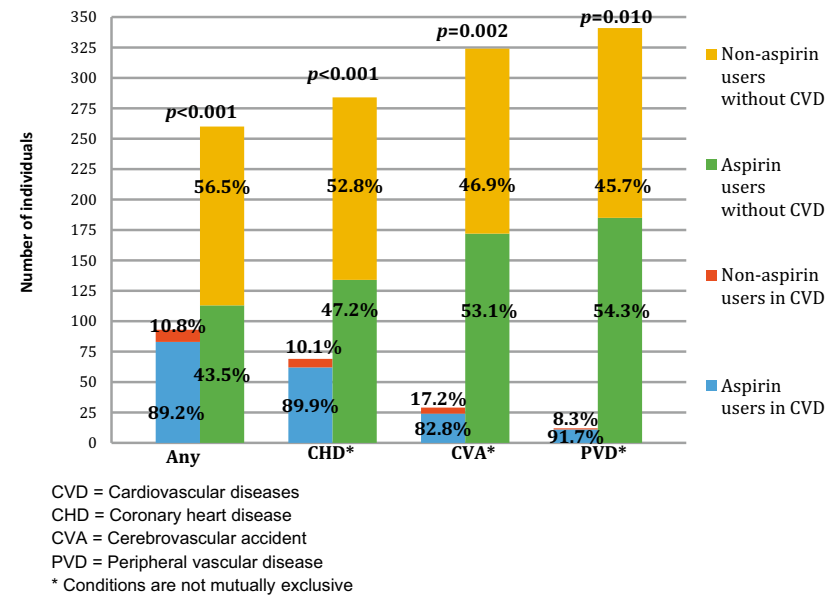

Fig. 2 Aspirin use in participants with cardiovascular disease (excluding oral anti-coagulants). CVD cardiovascular diseases, CHD coronary heart disease, CVA cerebrovascular accident, PVD peripheral vascular disease. *Conditions are not mutually exclusive also concluded that over a mean follow-up of 6.9 years, the number needed to harm was 1 major bleed in 261 , which counterbalanced the number needed to treat (253 patients), in order to prevent 1 major cardiovascular event.

A systematic review including all of the 11 RCTs aforementioned noted a $14.0 \%$ reduction in nonfatal stroke with the use of $\leq 100 \mathrm{mg}$ aspirin, on top of the well-established nonfatal MI decline. However, despite the addition of 18,369 participants in two other RCTs, the decrease in all-cause, and cardiovascular mortality remains insignificant [27]. The most recent ASCEND trial comparing 15,480 randomised patients with diabetes on either $100 \mathrm{mg}$ aspirin daily or placebo, suggested similar findings. The benefits of CVD risk reduction $(8.5 \%$ vs $9.6 \% ; p=0.01)$ was counterbalanced with major bleeding risks $(3.2 \%$ vs $4.1 \%, p=0.003)$ [11]. These results have been further borne out in the ASPREE study and the ARRIVE trial. Both of these studies excluded diabetic patients but still demonstrated risk: benefit neutrality for aspirin therapy without confirmed vascular disease $[9,10]$.

As of 2020, aspirin use for primary prevention is no longer recommended by most guidelines, $[14,16]$ except for the ADA which advise consideration of use for individuals with $>10 \%$ of 10 -year cardiovascular risk [13]. Our study documented that $40.0 \%$ and $70.0 \%$ of primary prevention persons under GP care only had less than $10 \%$ risk of 10 -year CHD risk and 10-year stroke risk, respectively. Similarly, $15.5 \%$ and $36.9 \%$ of the shared care participants had less than $10 \%$ risk of 10 -year CHD, and 10-year stroke risks, respectively (Fig. 3). According to the ADA guideline, [12] these individuals should not be prescribed aspirin. It was suggested that doctors tend to miscalculate individuals' CVD risk due to the lack of universal risk assessment tools or calculators [28]. Discrepancies in guidelines may result in confusion for physicians, and physicians may also be unlikely to discontinue a medication prescribed by other healthcare professionals.

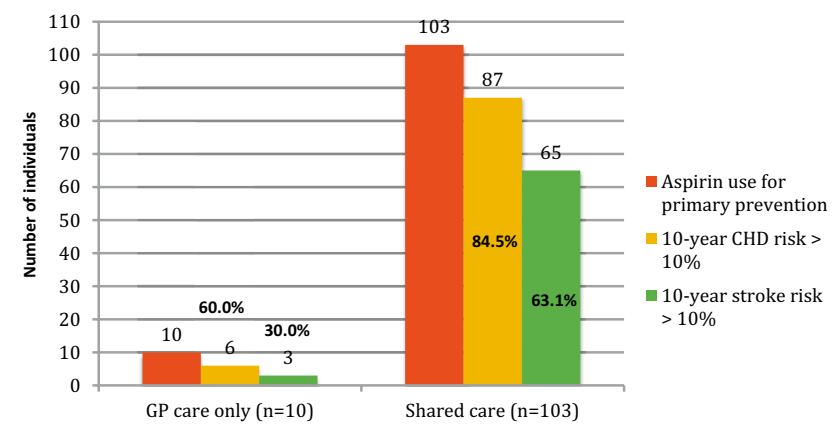

Fig. 3 10-year cardiovascular risk in participants taking aspirin for primary prevention. CHD coronary heart disease 
Upon review of the available literature to date, it is imperative to note that an increased risk for CVD in individuals with type 2 diabetes should not mandate aspirin use. Healthcare professionals are required to perform a thorough risk assessment tailored to each individual before prescribing aspirin therapy. Type 2 diabetes mellitus is associated with a greater number of comorbidities and complications, which inevitably, increase the cost of management. An Irish study done in 2010 indicated that persons with type 2 diabetes $\geq 65$ years who were covered by the General Medical Services scheme had a higher average annual pharmaceutical cost for management of comorbidities ( $€ 1238.67)$ in contrast to those without diabetes (€799.28) [29]. Therefore, patient education and strict adherence to therapeutic guidelines are recommended to prevent complications, and thereby also reduce costs to the healthcare system. Evidence-based indications should be implemented to improve appropriate drug usage, including aspirin, in individuals with diabetes. In addition, these individuals should have their medications reviewed thoroughly every year.

Some limitations of this research include the retrospective design of the study, incomplete data from clinical case notes, and measurement of the most recent, single clinical and laboratory data, which could result in over- or under-diagnoses. Aetiology of stroke was important as haemorrhagic stroke would preclude the need for aspirin, but it was not differentiated in this study. In addition, most studies adopted the Framingham risk score for 10-year CVD risk or the QRISK2 score, while this study used the UKPDS risk engine, as the latter is tailored for diabetes patients. A larger sample size and a longer study period would be recommended to provide better statistical results. A larger geographical catchment area also should be considered for future studies.

In conclusion, type 2 diabetes and CVD account for the most non-communicable diseases' deaths globally. Therefore, achievement of therapeutic targets for individuals with type 2 diabetes should be monitored closely and improved in order to reduce cardiovascular risk. A significant proportion of persons with diabetes should be, but were not, prescribed aspirin for secondary prevention. This is in contrast to the substantial population of those who should not be, but were on aspirin for primary prevention in this study. Both primary care and secondary care health professionals should re-evaluate their aspirin prescription among individuals with type 2 diabetes to ensure the utmost benefits are achieved.

Acknowledgements Statistical guidance was provided by University College Cork, as support for Medical School.

Author contribution Tan S.Y. contributed to writing research proposal, data collection, analysis of data, data interpretation, and writing up paper; O'Donovan A. contributed to data acquisition and data interpretation; Byrne S. reviewed research proposal; Cronin H. contributed to cardiovascular input and writing up paper; Tuthill A. contributed to writing research proposal, supervision of data collection, reviewed, and edited the manuscript.

Funding Open Access funding provided by the IReL Consortium

\section{Declarations}

Ethical approval The Clinical Research Ethics Committee (CREC) of the Cork Teaching Hospitals approved this study. All procedures performed this study involving human participants were in accordance with the ethical standards of the institutional and/or national research committee and with the 1964 Helsinki declaration and its later amendments or comparable ethical standards.

Conflict of interest The authors declare no competing interests.

Open Access This article is licensed under a Creative Commons Attribution 4.0 International License, which permits use, sharing, adaptation, distribution and reproduction in any medium or format, as long as you give appropriate credit to the original author(s) and the source, provide a link to the Creative Commons licence, and indicate if changes were made. The images or other third party material in this article are included in the article's Creative Commons licence, unless indicated otherwise in a credit line to the material. If material is not included in the article's Creative Commons licence and your intended use is not permitted by statutory regulation or exceeds the permitted use, you will need to obtain permission directly from the copyright holder. To view a copy of this licence, visit http://creativecommons.org/licenses/by/4.0/.

\section{References}

1. Nolan JJ, O'Halloran D, McKenna TJ et al (2006) The cost of treating type 2 diabetes (CODEIRE). Ir Med J 99(10):307-310

2. The 2016 global report on diabetes: World Health Organisation (WHO); 2016 [Available from: http://www.who.int/diabetes/ global-report/en/

3. Go AS, Mozaffarian D, Roger VL et al (2013) Executive summary: heart disease and stroke statistics-2013 update. A Report From the American Heart Association 127(1):143-152

4. Garcia MJ, McNamara PM, Gordon T, Kannell WB (1974) Morbidity and mortality in diabetics in the Framingham population: sixteen year follow-up study. Diabetes 23(2):105

5. Colwell JA, Nesto RW (2003) The platelet in diabetes: focus on prevention of ischemic events. Diabetes Care 26(7):2181-2188

6. Antiplatelet TC (1988) Secondary prevention of vascular disease by prolonged antiplatelet treatment. Br Med J (Clin Res Ed) 296(6618):320-331

7. Aspirin Therapy in Diabetes (2004) Diabetes Care 27(suppl 1):s72-s73

8. Haffner SM, Lehto S, Ronnemaa T et al (1998) Mortality from coronary heart disease in subjects with type 2 diabetes and in nondiabetic subjects with and without prior myocardial infarction. N Engl J Med 339(4):229-234

9. Gaziano JM, Brotons C, Coppolecchia R et al (2018) ARRIVE Executive Committee. Use of Aspirin to Reduce Risk of Inutial Vascular Events in patients at moderate risk of cardiovasculaer disease (ARRIVE): a randomised, double-blind, placebo-controlled trial. The Lancet. 392 (10152): 1036-1046

10. McNeil JJ, Nelson MR, Woods RL et al (2018) ASPREE Investigator Group. Effect of aspirin on all-cause mortality in the healthy 
elderly. New England Journal of Medicine. 379 (16): 15191528

11. Bowman L, Mafham M, Stevens W et al (2018) ASCEND Study Collaborative Group. A study of cardiovascular events in diabetes: characteristics of a randomised trial of aspirin and of omega-3 fatty acid supplemnetation in 15,480 people with diabetes. American Heart Journal 198: 135-144

12. American DA (1998) Aspirin therapy in diabetes. Clinical Diabetes 16(2):75

13. Disease C, Management R (2020) Standards of medical care in diabetes-2020. Diabetes Care 43(Supplement 1):S111

14. Harkins V (2016) ICGP, National Clinical Programme Diabetes Working Group, Department of Health and Children (DOHC), HSE. A practical guide to integrated type 2 diabetes care Irish College of general practitioners

15. Stevens RJ, Kothari V, Adler AI, Stratton IM (2001) United Kingdom Prospective Diabetes Study G. The UKPDS risk engine: a model for the risk of coronary heart disease in Type II diabetes (UKPDS 56). Clinical Science. 101(6):671-9

16. Joint British Societies' consensus recommendations for the prevention of cardiovascular disease (JBS3). Heart. 2014;100(Suppl 2):ii1

17. Peto R, Gray R, Collins R et al (1988) Randomised trial of prophylactic daily aspirin in British male doctors. BMJ 296(6618):313-316

18. Steering Committee of the Physicians' Health Study Research G. (1989) Final report on the aspirin component of the ongoing Physicians' Health Study. N. Eng. J. Med. 321(3):129-35

19. Kassoff A, Buzney SM, McMeel J et al (1992) Aspirin effects on mortality and morbidity in patients with diabetes mellitus: early treatment diabetic retinopathy study report 14 . JAMA 268(10):1292-1300

20. Hansson L, Zanchetti A, Carruthers SG et al (1998) Effects of intensive blood-pressure lowering and low-dose aspirin in patients with hypertension: principal results of the Hypertension Optimal Treatment (HOT) randomised trial. HOT Study Group The Lancet 351(9118):1755-1762
21. Framework TMRCsGPR (1998) Thrombosis prevention trial: randomised trial of low-intensity oral anticoagulation with warfarin and low-dose aspirin in the primary prevention of ischaemic heart disease in men at increased risk. The Lancet. 351(9098):233-41

22. Roncaglioni MC. Low-dose aspirin and vitamin $\mathrm{E}$ in people at cardiovascular risk: a randomised trial in general Practice. The Lancet.357(9250):89-95

23. Ridker PM, Cook NR, Lee IM et al (2005) A randomized trial of low-dose aspirin in the primary prevention of cardiovascular disease in women. N Engl J Med 352(13):1293-1304

24. Sanmuganathan PS, Ghahramani P, Jackson PR et al (2001) Aspirin for primary prevention of coronary heart disease: safety and absolute benefit related to coronary risk derived from meta-analysis of randomised trials. Heart 85(3):265-271

25. Bartolucci AA, Tendera M, Howard G (2011) Meta-analysis of multiple primary prevention trials of cardiovascular events using aspirin. Am J Cardiol 107(12):1796-1801

26. Berger JS, Lala A, Krantz MJ et al (2011) Aspirin for the prevention of cardiovascular events in patients without clinical cardiovascular disease: a meta-analysis of randomized trials. Am Heart J 162(1):115-24.e2

27. Guirguis-Blake JM, Evans CV, Senger CA et al (2016) Aspirin for the primary prevention of cardiovascular events: a systematic evidence review for the u.s. preventive services task force. Annals of Internal Medicine. 164(12):804-13

28. Nansseu JR, Noubiap JJ (2015) Aspirin for primary prevention of cardiovascular disease. Thromb J 13:38

29. O'Shea M, Teeling M, Bennett K (2013) The prevalence and ingredient cost of chronic comorbidity in the Irish elderly population with medication treated type 2 diabetes: a retrospective cross-sectional study using a national pharmacy claims database. BMC Health Serv Res 13:23

Publisher's Note Springer Nature remains neutral with regard to jurisdictional claims in published maps and institutional affiliations. 